January 2016

\title{
Evaluation of the uptake and impact of neonatal vitamin A supplementation delivered through the Lady Health Worker programme on neonatal and infant morbidity and mortality in rural Pakistan: an effectiveness trial
}

\author{
Sajid Soofi \\ Aga Khan University \\ Shabina Ariff \\ Aga Khan University \\ Kamran Sadiq \\ Aga Khan University \\ Atif Habib \\ Aga Khan University, atif.habib@aku.edu \\ Zaid Bhatti \\ Aga Khan University
}

\section{Recommended Citation}

Soofi, S., Ariff, S., Sadiq, K., Habib, A., Bhatti, Z., Ahmad, I., Hussain, M., Ali, N., Cousens, S., Bhutta, Z. (2016). Evaluation of the uptake and impact of neonatal vitamin A supplementation delivered through the Lady Health Worker programme on neonatal and infant morbidity and mortality in rural Pakistan: an effectiveness trial. Archives of Disease in Childhood, 102(3), 216-223.

Available at: https://ecommons.aku.edu/pakistan_fhs_mc_women_childhealth_paediatr $/ 248$ 
See next page for additional authors

Follow this and additional works at: https:/ / ecommons.aku.edu/ pakistan_fhs_mc_women_childhealth_paediatr

Part of the Pediatrics Commons 


\section{Authors}

Sajid Soofi, Shabina Ariff, Kamran Sadiq, Atif Habib, Zaid Bhatti, Imran Ahmad, Masawar Hussain, Nabeela Ali, Simon Cousens, and Zulfiqar A Bhutta 


\title{
Evaluation of the uptake and impact of neonatal vitamin A supplementation delivered through the Lady Health Worker programme on neonatal and infant morbidity and mortality in rural Pakistan: an effectiveness trial
}

\author{
Sajid Soofi, ${ }^{1}$ Shabina Ariff, ${ }^{1}$ Kamran Sadiq, ${ }^{1}$ Atif Habib, ${ }^{1}$ Zaid Bhatti, ${ }^{1}$ Imran Ahmad, ${ }^{1}$ \\ Masawar Hussain, ${ }^{1}$ Nabeela Ali, ${ }^{2}$ Simon Cousens, ${ }^{3}$ Zulfiqar A Bhutta ${ }^{1,3,4}$
}

\begin{abstract}
${ }^{1}$ Women \& Child Health Division, The Aga Khan University, Karachi, Pakistan ${ }^{2}$ John Snow International Research Institute, Islamabad, Pakistan

${ }^{3}$ London School of Hygiene and Tropical Medicine, London, UK

${ }^{4}$ Centre for Global Child Health, The Hospital for Sick Children, Toronto, UK
\end{abstract}

\section{Correspondence to} Professor Zulfiqar A Bhutta, Centre of Excellence in Women and Child Health, Aga Khan University, Stadium Road, Karachi 74800, Pakistan; zulfiqar.bhutta@aku.edu

Received 27 January 2016 Revised 31 May 2016 Accepted 4 June 2016 Published Online First 28 June 2016

\section{CrossMark}

To cite: Soofi S, Ariff $S$, Sadiq K, et al. Arch Dis Child 2017;102:216-223.

\begin{abstract}
Background Despite evidence for the benefits of vitamin A supplementation (VAS) among children 6 to 59 months of age, the feasibility of introduction and potential benefit of VAS in the neonatal period in public health programmes is uncertain.

Objective The primary objective was to evaluate the feasibility and effectiveness of early neonatal VAS (single dose of 50000 international units within $48-72$ hours after birth) delivered through the public sector Lady Health Worker (LHW) programme in rural Pakistan and to document its association with a reduction in mortality at 6 months of age.
\end{abstract}

Methods A community-based, cluster randomised, placebo-controlled trial was undertaken in two districts of rural Pakistan. LHWs dispensed vitamin A/placebo in identical capsules to newborn infants within 4872 hours of birth. Follow-up visits were undertaken at 1 week of age and every 4 weeks thereafter until 6 months of age.

Results Of a total of 15433 consecutive pregnancies among eligible women of reproductive age, 13225 pregnancies were registered, 12218 live births identified and 11028 newborn infants reached by LHWs. Of these, $5380(49 \%)$ received neonatal VAS and 5648 (51\%) placebo. The LHWs successfully delivered the capsules to $79 \%$ of newborns within 72 hours of birth with no significant adverse effects. Although the proportion of days observed with symptoms of fever, diarrhoea or rapid breathing were lower with neonatal VAS, these differences were not statistically significant. Mortality rates in the two groups were comparable at 6 months of age.

Conclusions While our study demonstrated that neonatal VAS was safe and could be feasibly delivered by LHWs in Pakistan as part of their early postnatal visits, the overall lack of benefit on neonatal and 6month morbidity and mortality in our population suggests the need for further evaluation of this intervention in populations at risk.

Trial registration number ClinicalTrials.gov NCT00674089.

\section{INTRODUCTION}

Globally, 6.3 million children die each year before reaching their fifth birthday and almost $44 \%$ of these deaths occur during the first 28 days of life. ${ }^{1}$ Annually, 2.9 million neonatal deaths are reported

\section{What is already known on this topic?}

- Vitamin A supplementation among children 6 to 59 months of age has been shown to reduce under-five child mortality in populations at risk of vitamin A deficiency.

- There is mixed evidence of the impact of vitamin A supplementation in the newborn period on mortality among children by 6 months of age, with studies in South Asia (India, Philippines and Bangladesh) showing a reduction in mortality but little evidence of a similar effect among studies in Africa.

- A major issue in relation to neonatal vitamin A dosing is the feasibility of administering such doses as part of public sector programmes.

\section{What this study adds?}

- Our study was designed as a feasibility study with possible inclusion within the Lady Health Worker (LHW) programme of activities and early post-natal visits in two rural districts of Pakistan with populations at risk of vitamin $A$ deficiency.

- The LHWs were able to administer the vitamin A dose to a large proportion (79\%) of newborn infants at home within 72 hours of birth with no significant adverse effects noted.

- There was no impact of neonatal Vitamin A supplementation on mortality at 6 months of age, although the proportion of days observed with fever, diarrhoea or rapid breathing were lower with neonatal vitamin A supplementation.

globally that are largely preventable. ${ }^{2} 3$ Maternal and childhood undernutrition contributes to almost $45 \%$ of child deaths and the association of vitamin A deficiency with excess risk of child morbidity and mortality after 6 months of age is well recognised. ${ }^{4}$ Vitamin A supplementation (VAS) is recommended as a key lifesaving intervention for children aged 
6-59 months in populations at risk of vitamin A deficiency. ${ }^{5}$ Given widespread maternal vitamin A deficiency in some regions and the fact that a large proportion of child deaths occur among young infants, it is plausible that alleviation of vitamin A deficiency among young infants could be beneficial. Although some studies have reported a beneficial impact on infant mortality in south Asia and among populations with a relatively high prevalence of maternal vitamin A deficiency, ${ }^{6} 7$ other recent studies have shown modest benefits. ${ }^{8}$ These findings cannot be generalised to the global context as other randomised controlled trials in similar settings have not shown any benefits. $^{9-12}$

Pakistan has relatively high neonatal and under-5 child mortality rates compared with other south Asian countries ${ }^{13}$ and a persistent high burden of maternal and child vitamin A deficiency at the population level. ${ }^{14}$ In 1994 the Government of Pakistan launched a national programme for family planning and primary care, the so-called Lady Health Worker (LHW) programme, with the objective of improving health and access to essential primary health care in rural and selected peri-urban communities. The LHWs are community-based health workers with secondary education who are trained and employed by the Ministry of Health to deliver these services. ${ }^{15}$ Each LHW is responsible for a population of around 1000. The LHWs register all pregnant women (pregnancies) in their catchment area and, as part of their assignments, are supposed to undertake a postnatal visit at the household level within 72 hours of birth, although the overall coverage of this intervention is very low. ${ }^{16}$ LHWs are supervised by Lady Health Supervisors (LHSs) employed at a Basic Health Unit (BHU). Each LHS is typically responsible for 20-25 LHWs in her catchment area and supervises their overall work and monthly progress reports. The programme is operational throughout the country and currently employs over 100000 LHWs. In June 2011, as part of a constitutional amendment, the LHW programme was devolved to the provinces. The national LHW programme is the mainstay of many primary care preventive interventions in rural settings and, while a number of newborn interventions have been piloted through this programme, ${ }^{17} 18$ there are none that have evaluated the feasibility and effectiveness of an early postnatal visit and provision of a vitamin A supplement.

We undertook a community-based, placebo-controlled, cluster randomised trial in rural Pakistan to evaluate the feasibility of delivering early neonatal vitamin A (single dose of 50000 international units (IU) or placebo) through LHWs and its potential impact on health outcomes and mortality at 6 months of age.

\section{METHODS}

\section{Context and population}

The trial was conducted between January 2007 and October 2010 in two rural districts, Sukkur and Jhelum, in Pakistan, representing a typical mix of peri-urban and rural multiethnic populations of 1108000 and 1048000 , respectively. The intervention was developed and implemented in partnership with the LHW programme and the study areas selected on the basis of demographic patterns and population mix, number of functional LHWs and approval by the LHW programme for partnership and data sharing.

The LHWs and LHSs underwent 3 days of separate training at the beginning of the project. The training focused on understanding the programme objectives for commodity delivery, appropriate storage (light protection) for the capsules, transport and administration of capsules, recognition and reporting of adverse events, morbidities and hospitalisations. The LHWs were trained to record morbidities reported by mothers covering the 2 weeks prior to the visit and to examine the newborn/ infant for relevant morbidities using the standard WHO/IMCI algorithms for classification of respiratory tract infections, sepsis and diarrhoea. Refresher trainings (1 day) were provided during the course of the study on a quarterly basis.

\section{Study design, cluster definition, sample size estimation and allocation}

A baseline census of the study areas in both districts was undertaken to enumerate households, collect socioeconomic and demographic data and determine LHW density. Study clusters were defined as the catchment population of one LHW, usually an average population of 1000 covering 100-150 households. An external consultant generated the computerised allocation sequence of clusters to each intervention group using Epi Info 3.5.3 with restricted randomisation based on population size, expected births and LHW presence.

Given the reported rural infant mortality rates from the Pakistan Demographic and Health Survey (2006) ${ }^{19}$ in the two districts of about 80 per 1000 live births and a projected $25 \%$ reduction in mortality at 6 months of age, we estimated that 400 clusters (200 in each group, averaging 30 births per cluster annually) would be required to demonstrate this impact with $80 \%$ power and $5 \%$ significance. $^{20}$

\section{Study procedures and data collection}

Pregnant women were registered by LHWs as part of their regular activities and standard operating procedures. Families were encouraged to report a birth as soon as it occurred and LHWs also liaised with the local traditional birth attendants to identify births. The LHWs were encouraged to visit the birth household (within 72 hours) following notification of birth to obtain written informed consent, collect information on the mother and newborn, and to administer a single dose of oral vitamin A (50 $000 \mathrm{IU})$ or placebo to the infant. The LHW also counselled the mother on basic preventive measures and encouraged her to breast feed the newborn immediately after capsule administration to ensure consumption of the entire dose. All live born infants within participating villages were potentially eligible for inclusion in the study. Infants with obvious congenital malformations and birth weight $<1500 \mathrm{~g}$ were excluded. No vitamin A doses were administered in facilities, and for facility births the LHW visited the household at least once within 72 hours of birth and, if the mother and infant pair had returned from the hospital, she administered the neonatal dose.

The LHW returned empty vitamin A capsules to the LHS who kept an inventory of the repository and provided supervision, capsule replenishment and monitored the LHW's activities as per routine. The LHW repeated the home visits on days 7 and 28 and thereafter at monthly intervals until 6 months of age. On the first follow-up visit at day 7 (unless passively reported earlier by the family), the LHW collected information on any adverse events reported by the mother after vitamin A administration and thereafter information was collected on neonatal illnesses, care seeking, hospitalisations and any deaths at the monthly visits. At each visit the infant's vital status was evaluated, signs of illness (if any) recorded and action taken as per LHW programme policies.

Blood samples from a randomly selected subset of 450 infants were obtained at 6 months of age and analysed for serum retinol concentration. The samples were collected at the household level by trained phlebotomists, separated and frozen in the 
field and transported to the Nutrition Research Laboratory at the Aga Khan University for analysis using standard methods. ${ }^{21}$

\section{Masking, distribution of capsules and quality control}

The vitamin A capsule contained 50000 IU retinol palmitate in soybean oil and the placebo contained $10 \mathrm{IU}$ vitamin $\mathrm{E}$ in soybean oil. The capsules were identical in appearance (Banner Pharmacaps, Alberta, Canada) and supplied in bulk through the courtesy of the Micronutrient Initiative (Ottawa, Canada). The capsules were stored at the Aga Khan University (AKU) pharmacy with close temperature regulation and light protection, and supplied to the districts in similar containers with unique codes representing clusters and specific LHWs. The content and allocation of the capsules were masked from the investigators and field staff and the container codes were only known to the external consultant responsible for cluster randomisation and the chair of the Data Safety and Monitoring Board (DSMB). The containers (vitamin A and placebo) were covered with aluminium foil and transported at room temperature to the field at monthly intervals based on requirement and consumption. Research supervisors carried out random checks of vitamin A stores to ensure compliance. Strict fidelity of allocation of vitamin A (or placebo) containers by LHWs was maintained by the AKU pharmacy.

\section{Data capture, trial safety monitoring and analysis}

Twelve independent teams of data collectors (each with six members including a supervisor) conducted a cross-sectional household survey of the entire catchment population at baseline and thereafter at 3-monthly intervals. The data collectors were provided with 3 days of training on data collection instruments and communication skills. These teams collected information on

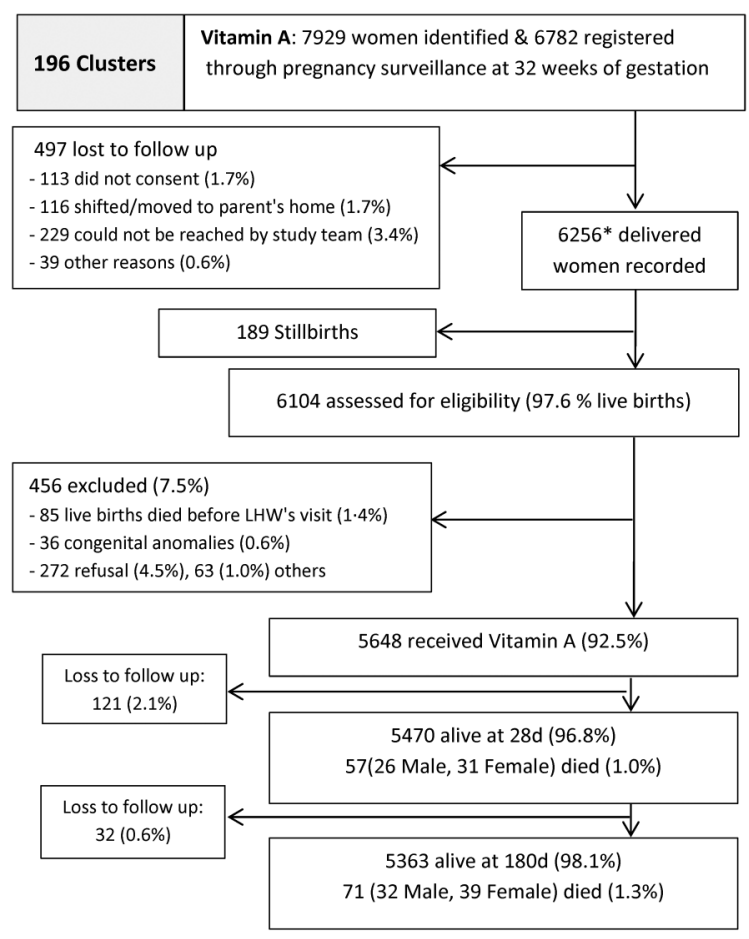

live births, deaths, migrations and also obtained information on causes of deaths through verbal autopsies. They obtained information on receipt of vitamin A by newborn infants from mothers/family elders. Additionally, a separate data collection team visited the household at 2 -weekly intervals to gather data on morbidity and collect details of diarrhoeal episodes, respiratory problems and febrile episodes that the neonate/infant encountered during the preceding 2 weeks.

The primary outcome was all-cause mortality by 6 months of age Secondary outcomes were common morbidities (febrile illness, diarrhoea or pneumonia). Infant deaths were identified at home visits by LHWs and also verified by the independent data collection team of all recruited children. In case of discrepancy between LHW record and independent study data collectors, the study supervisor verified deaths by household visits. Cause of death was determined from an independent review of verbal autopsies by two paediatricians. Disagreements were referred to a third assessor experienced in verbal autopsies.

All data files were double entered in MS FoxPro and analysed using STATA V.12, in addition to mortality outcomes at 6 months of age and morbidity data. The proportion of monthly visits at which a child was reported to have had morbidity was compared between the two arms using a Generalised Estimating Equation, accounting for clusters, controlling for the month of the visit (as a proxy for age).

The trial was overseen by a DSMB consisting of four members with expertise in cluster randomised trials, newborn and child health and medical statistics. The DSMB had access to allocation codes and undertook blinded safety analyses to check for any excess in mortality or severe morbidity outcomes. The DSMB met three times during the course of the study to assess progress, adverse events and key outcomes. The Chair of the

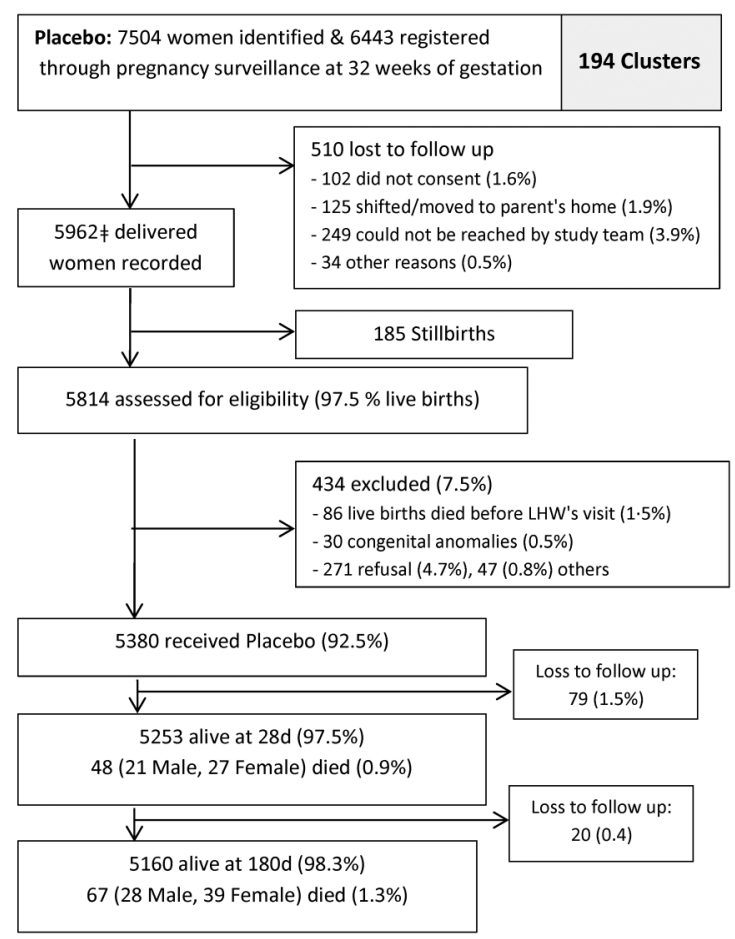

*2 twins (1LB, 1SB), 31 twins (LB) \& 2 triplets (LB)

$\neq 34$ twins (LB), 1 twin (SB) \& 1 triplet (LB)

Figure 1 Flow diagram for the neonatal vitamin A study (Pakistan). * Two twins (1LB, 1SB), 31 twins (LB) and two triplets (LB). \#24 twins (LB), one twin (SB) and one triplet (LB). LB, live birth; SB, stillbirth. 
Table 1 Sociodemographic characteristics of the infants' families pre-randomisation (baseline survey), $\mathrm{n}(\%)$

\begin{tabular}{|c|c|c|}
\hline Characteristic & Placebo $(n=25474)$ & VAS $(n=28431)$ \\
\hline Married women aged $15-49$ years & 23877 & 26076 \\
\hline Median (IQR) age, years & $30(25-40)$ & $31(26-40)$ \\
\hline Maternal literacy & $6623(28 \%)$ & $7544(29 \%)$ \\
\hline Household density & 6.2 & 6.1 \\
\hline \multicolumn{3}{|l|}{ Monthly household income } \\
\hline$\leq 6000$ PKR & $16437 / 25033(67 \%)$ & $18814 / 28260(68 \%$ \\
\hline$>6000$ PKR & $8227 / 25033(33 \%)$ & $9028 / 28260(32 \%)$ \\
\hline Median (IQR) & $5000(3000-8000)$ & $5000(3000-7000)$ \\
\hline \multicolumn{3}{|l|}{ Nature of construction of household } \\
\hline Pucca (concrete) & $14289 / 25431$ (56\%) & 12 015/28390 (42\% \\
\hline Semi-pucca & $5063 / 25431(20 \%)$ & $11251 / 28390(40 \%$ \\
\hline Katcha & $5623 / 25431(22 \%)$ & $4774 / 28390(17 \%)$ \\
\hline Others & $456 / 25431(2 \%)$ & $350 / 28390(1 \%)$ \\
\hline \multicolumn{3}{|l|}{ Living rooms in the house } \\
\hline 1 & $8800 / 25191(35 \%)$ & $8699 / 28272(31 \%)$ \\
\hline$\geq 2$ & $16365 / 25191(65 \%)$ & $19561 / 28272(69 \%$ \\
\hline \multicolumn{3}{|l|}{ Main cooking fuel } \\
\hline Electricity & $3279 / 25474(13 \%)$ & $3742 / 28431(13 \%)$ \\
\hline Natural gas & $4829 / 25474(19 \%)$ & $3590 / 28431(13 \%)$ \\
\hline Firewood & 17 094/25 474 (67\%) & $20764 / 28431(73 \%$ \\
\hline Others & $216 / 25474(1 \%)$ & $289 / 28431(1 \%)$ \\
\hline Household with electricity & $24470 / 25425(96 \%)$ & $27816 / 28399(98 \%$ \\
\hline \multicolumn{3}{|l|}{ Main drinking water source } \\
\hline Well/hand pump & $4552 / 25429(18 \%)$ & 4826/28 $387(17 \%)$ \\
\hline Communal tap/motor pump & $14978 / 25429$ (59\%) & 17 032/28 $387(60 \%$ \\
\hline Others & $5900 / 25429(23 \%)$ & $6529 / 28387(23 \%)$ \\
\hline \multicolumn{3}{|l|}{ Type of latrine } \\
\hline Open fields & $9133 / 25427(36 \%)$ & $9918 / 28385(35 \%)$ \\
\hline Pit latrine & $3983 / 25427(16 \%)$ & $4449 / 28385(16 \%)$ \\
\hline WC connected to public sewerage/open drains & $12253 / 25427(48 \%)$ & $13970 / 28385(49 \%$ \\
\hline
\end{tabular}

DSMB gave permission to unmask the study after completion of the trial, data locking and analysis of primary outcomes. While data on primary outcomes were available by November 2011, given the LHW programme devolution to the provinces in mid-2011, permission to share the results from the LHW programmes in Sindh and Punjab took considerably longer and was finally received in April 2013.

\section{RESULTS}

The cross-sectional surveys identified 15433 pregnant women in the catchment area during the course of the study, of which the LHWs registered a total of 13225 pregnant women (86\%). Assessment of gestational age was based on the maternal recall of her last menstrual period. Birth outcomes were recorded for 12218 women (92\%) while 1007 (8\%) were lost to follow-up and a further $374(3.1 \%)$ pregnancies ended in stillbirths. The remaining pregnancies resulted in 11918 live born babies. Of these, 171 live born babies (1.4\%) died before the LHW conducted the first postnatal visit, with the majority of the neonatal deaths $(66.3 \%$ in the placebo group and $52.9 \%$ in neonatal VAS group) occurring within the first 24 hours of life. A further 609 $(5.1 \%)$ neonates were excluded for other reasons (figure 1). Altogether, 11028 (92.5\%) of all live born newborns were randomised to receive either placebo or neonatal VAS capsules, of which $10286(86.3 \%)$ infants were followed up until death or 6 months of age.
The baseline characteristics of the two study arms were comparable (table 1). Study participants in both the groups were also comparable with respect to timing of interventions, gender and BCG vaccination status. Overall, the majority of the deliveries $(55.2 \%)$ occurred at home, mostly attended by traditional birth attendants. Among the newborns that had their weights assessed at birth, mean recorded birth weights were $2.82 \mathrm{~kg}$ in the placebo arm and $2.81 \mathrm{~kg}$ in the neonatal VAS arm; $8.3 \%$ of infants were low birth weight $(<2.5 \mathrm{~kg})$ in the placebo arm compared with $9.3 \%$ in the neonatal VAS arm (table 2). Newborn infants in the community receive their first dose of polio and BCG at the BHUs by government employed vaccinators and the BCG vaccination status for the two groups was comparable.

The LHWs successfully delivered the capsules to the majority (80\%) of newborns (neonatal VAS/placebo) within 72 hours of birth; $60 \%$ received them within 24 hours. A total of 26 adverse events were documented in the two groups, 10 in the neonatal VAS group and 16 in the placebo group $(p=0.19)$. Of the 10 adverse events in the neonatal VAS group, seven were diarrhoeal episodes. Only one case of bulging fontanel was reported in each group (table 3 ).

We did not measure maternal or neonatal serum retinol concentrations at birth or recruitment. However, among the subset of 449 infants sampled at 6 months of age, there was no evidence of a difference in mean serum retinol concentrations 


\section{Original article}

Table 2 Baseline characteristics of mothers and delivery and newborn care practices (post-randomisation)

\begin{tabular}{|c|c|c|}
\hline Characteristic & Placebo & VAS \\
\hline Baseline characteristics of mothers & $(n=5962)$ & $(n=6256)$ \\
\hline \multicolumn{3}{|l|}{ ANC visits during current pregnancy } \\
\hline Never & $474 / 5693(8 \%)$ & $551 / 5947(9 \%)$ \\
\hline $1-3$ & $2658 / 5693(47 \%)$ & $2608 / 5947(44 \%)$ \\
\hline$>3$ & $2561 / 5693(45 \%)$ & $2788 / 5947(47 \%)$ \\
\hline \multicolumn{3}{|c|}{ Iron or multivitamin supplementation during current pregnancy } \\
\hline Yes & $4342 / 5962(73 \%)$ & $4579 / 6256(73 \%)$ \\
\hline \multicolumn{3}{|l|}{ Addiction during pregnancy period } \\
\hline Tobacco & $64(1 \%)$ & $52(1 \%)$ \\
\hline Non-smoking tobacco* & $182(3 \%)$ & $143(2 \%)$ \\
\hline \multicolumn{3}{|l|}{ Reproductive history } \\
\hline Gravida, mean (SD) & $2.51(2.57)$ & $2.49(2.78)$ \\
\hline Delivery and newborn care practices & $(n=5380)$ & $(n=5648)$ \\
\hline \multicolumn{3}{|l|}{ Place of delivery } \\
\hline At home & $2892 / 5341(54 \%)$ & $3169 / 5632(56 \%)$ \\
\hline Government health facility & $715 / 5341(13 \%)$ & $838 / 5632(15 \%)$ \\
\hline Private hospital & $930 / 5341(17 \%)$ & $908 / 5632(16 \%)$ \\
\hline Private clinic & $804 / 5341(15 \%)$ & $717 / 5632(13 \%)$ \\
\hline \multicolumn{3}{|l|}{ Delivery attended } \\
\hline Skilled providert & $2779 / 5346(52 \%)$ & $2800 / 5628(50 \%)$ \\
\hline Unskilled & $339 / 5346(48 \%)$ & $2828 / 5628(50 \%)$ \\
\hline Use of clean delivery kits & $3508 / 5291(66 \%)$ & $3604 / 5420(67 \%)$ \\
\hline \multicolumn{3}{|l|}{ Gender of child } \\
\hline Male & $2772 / 5378(52 \%)$ & $2965 / 5645(53 \%)$ \\
\hline Female & $2606 / 5378(49 \%)$ & $2680 / 5645(48 \%)$ \\
\hline \multicolumn{3}{|l|}{ Birth weight (kg) } \\
\hline$<2.5$ & $306 / 3693(8.3 \%)$ & $331 / 3549(9.3 \%)$ \\
\hline$\geq 2.5$ & $3387 / 3693(92 \%)$ & $3218 / 3549(91 \%)$ \\
\hline Birth weight mean (SD), kg & $2.82(0.72)$ & $2.81(0.74)$ \\
\hline \multicolumn{3}{|l|}{ BCG given to newborn after birth } \\
\hline Yes & $1614 / 5370(30 \%)$ & $1629 / 5630(29 \%)$ \\
\hline
\end{tabular}

Table 3 Adverse events following vitamin A supplementation (VAS), n (\%)

\begin{tabular}{lll}
\hline & Placebo & VAS \\
\hline Adverse event reported within 1 week of supplementation & $16 / 5380(0.3 \%)$ & $\begin{array}{l}10 / 5648(0.2 \%) \\
(95 \% \mathrm{Cl} 0.1 \text { to } 0.3)\end{array}$ \\
Distribution of adverse events & $(95 \% \mathrm{Cl} 0.2$ to 0.5$)$ & \\
Loose motion & $8 / 16(50 \%)$ & $7 / 10(75 \%)$ \\
& $(95 \% \mathrm{Cl} 23$ to 77$)$ & $(95 \% \mathrm{Cl} 39$ to 100$)$ \\
Vomiting & $2 / 16(12.5 \%)$ & $1 / 10(10.0 \%)$ \\
& $(95 \% \mathrm{Cl} 0$ to 30$)$ & $(95 \% \mathrm{Cl} 0$ to 31$)$ \\
Bulging fontanel & $1 / 16(6 \%)$ & $1 / 10(10 \%)$ \\
& $(95 \% \mathrm{Cl} 0$ to 19$)$ & $(95 \% \mathrm{Cl} 0$ to 31$)$ \\
Unconsciousness & $1 / 16(6 \%)$ & $0 / 10(0 \%)$ \\
& $(95 \% \mathrm{Cl} 0$ to 19$)$ & $(95 \% \mathrm{Cl}--)$ \\
Seizures & $1 / 16(6 \%)$ & $1 / 10(10 \%)$ \\
& $(95 \% \mathrm{Cl} 0$ to 19$)$ & $(95 \% \mathrm{Cl} 0$ to 31$)$ \\
Fever & $3 / 16(19 \%)$ & $0 / 10(0 \%)$ \\
& $(95 \% \mathrm{Cl} 0$ to 40$)$ & $(95 \% \mathrm{Cl}--)$ \\
Hospitalisation during first 6 months of life & $185 / 5380(3.4 \%)$ & $185 / 5648(3.3 \%)$ \\
& $(95 \% \mathrm{Cl} 2.9$ to 3.9$)$ & $(95 \% \mathrm{Cl} 2.8$ to 3.7$)$ \\
\hline
\end{tabular}

Data are $\mathrm{n}$ or $\mathrm{n}(\%)$. 
Table 4 Serum retinol level at 6 months of age

\begin{tabular}{llll}
\hline & Placebo $(\mathbf{n}=\mathbf{2 1 9})$ & VAS ( $\mathbf{n = 2 3 0 )}$ & \\
\hline $\begin{array}{l}\text { Retinol }(\mu \mathrm{g} / \mathrm{dL}) \\
\text { Severe deficiency }(<10 \mu \mathrm{g} / \mathrm{dL})\end{array}$ & & \\
& $19 / 219(9 \%)$ & $79 / 230(4 \%)$ & $(95 \% \mathrm{Cl} 1$ to 6$)$ \\
Deficiency $(<20 \mu \mathrm{g} / \mathrm{dL})$ & $(95 \% \mathrm{Cl} 5$ to 12$)$ & $79 / 230(34 \%)$ & $(95 \% \mathrm{Cl} 28$ to 41$)$ \\
& $82 / 219(37 \%)$ & $26.9(0.99)$ & $(95 \% \mathrm{Cl} 25$ to 29$)$ \\
Mean (SE) & $(95 \% \mathrm{Cl} 31$ to 44$)$ & $23.7(16.8$ to 32.8$)$ \\
& $25.7(0.87)$ & & 0.04 \\
\hline
\end{tabular}

Data are $n, n(\%)$ or mean (SE) or median (IQR).

VAS, vitamin A supplementation.

Table 5 Reported morbidities by treatment arm

\begin{tabular}{lcc}
\hline & Placebo & VAS \\
\hline Proportion of monthly visits at which child was reported to have been ill in preceding 30 days & \\
Number of monthly visits completed & 26571 & 27465 \\
Fever & $8130 / 26571(31 \%)$ & $7928 / 27465(29 \%)$ \\
Diarrhoea & $2609 / 26571(10 \%)$ & $2272 / 27465(8 \%)$ \\
Rapid breathing & $740 / 26571(2.8 \%)$ & $617 / 27465(2.3 \%)$ \\
Severe pneumonia & $245 / 26571(0.9 \%)$ & $121 / 27465(0.4 \%)$
\end{tabular}

Data are $n, n(\%)$ or mean proportion of days with illness.

*OR estimated using Generalised Estimating Equation to account for cluster randomisation and adjusted for month of visit.

VAS, vitamin A supplementation.

Table 6 Effect of vitamin A post-supplementation on primary outcome: overall and stratified by sex

\begin{tabular}{|c|c|c|c|c|c|c|c|c|c|}
\hline & \multicolumn{4}{|c|}{ Number of newborns supplemented } & \multicolumn{2}{|l|}{ Risk per 1000 live births } & \multirow{3}{*}{$\begin{array}{l}\text { OR } \\
(95 \% \mathrm{CI})\end{array}$} & \multirow{3}{*}{ p Value } & \multirow{3}{*}{$\begin{array}{l}\text { Effect size } \\
(95 \% \mathrm{Cl})\end{array}$} \\
\hline & \multicolumn{2}{|c|}{ Placebo } & \multicolumn{2}{|l|}{ VAS } & \multirow[b]{2}{*}{ Placebo } & \multirow[b]{2}{*}{ VAS } & & & \\
\hline & Events & No of newborns & Events & No of newborns & & & & & \\
\hline \multicolumn{10}{|c|}{ Mortality (post-supplementation) } \\
\hline \multicolumn{10}{|c|}{ A. Neonatal mortality (0-28 days) } \\
\hline Overall & 48 & 5380 & 57 & 5648 & $9(95 \% \mathrm{Cl} 7$ to 12$)$ & $10(95 \% \mathrm{Cl} 8$ to 13$)$ & 1.13 (0.76 to 1.66$)$ & 0.6 & $0.06(-0.14$ to 0.28$)$ \\
\hline Male & 21 & 2774 & 26 & 2966 & $7.6(95 \% \mathrm{Cl} 5$ to 12$)$ & $8.8(95 \% \mathrm{Cl} 6$ to 13$)$ & 1.15 (0.65 to 2.06$)$ & 0.6 & $0.08(-0.23$ to 0.39$)$ \\
\hline Female & 27 & 2606 & 31 & 2682 & $10.4(95 \% \mathrm{Cl} 7$ to 15$)$ & $11.6(95 \% \mathrm{Cl} 8$ to 16$)$ & 1.11 (0.66 to 1.87 ) & 0.7 & $0.06(-0.22$ to 0.34$)$ \\
\hline \multicolumn{10}{|c|}{ B. Mortality (0-6 months) } \\
\hline Overall & 115 & 5380 & 128 & 5648 & $21(95 \% \mathrm{Cl} 18$ to 26$)$ & $23(95 \% \mathrm{Cl} 19$ to 27$)$ & 1.06 (0.82 to 1.37$)$ & 0.6 & $0.03(-0.10$ to 0.17$)$ \\
\hline Male & 49 & 2774 & 58 & 2966 & $17.7(95 \% \mathrm{Cl} 13$ to 23$)$ & $19.6(95 \% \mathrm{Cl} 15$ to 25$)$ & 1.10 (0.75 to 1.62$)$ & 0.6 & $0.05(-0.15$ to 0.26$)$ \\
\hline Female & 66 & 2606 & 70 & 2682 & $25.3(95 \% \mathrm{Cl} 20$ to 32$)$ & $26.1(95 \% \mathrm{Cl} 21$ to 33$)$ & 1.03 (0.73 to 1.44$)$ & 0.9 & $0.01(-0.17$ to 0.20$)$ \\
\hline \multicolumn{10}{|c|}{ Mortality (pre- and post-supplementation) } \\
\hline \multicolumn{10}{|c|}{ C. Neonatal mortality (0-28 days) } \\
\hline Overall & 134 & 5706 & 142 & 5970 & $23(95 \% \mathrm{Cl} 20$ to 28$)$ & 24 (95\% Cl 20 to 28$)$ & 1.01 (0.80 to 1.27$)$ & 0.9 & $0.007(-0.12 .0 .13)$ \\
\hline Male & 73 & 2959 & 75 & 3145 & 25 (95\% Cl 20 to 31$)$ & $24(95 \% \mathrm{Cl} 19$ to 30$)$ & 0.96 (0.69 to 1.33$)$ & 0.8 & $-0.01(-0.19$ to 0.16$)$ \\
\hline Female & 61 & 2747 & 67 & 2825 & $22.2(95 \% \mathrm{Cl} 17$ to 28$)$ & $23.7(95 \% \mathrm{Cl} 19$ to 30$)$ & 1.06 (0.75 to 1.52$)$ & 0.7 & $0.03(-0.15$ to 0.23$)$ \\
\hline \multicolumn{10}{|c|}{ D. Mortality (0-6 months) } \\
\hline Overall & 201 & 5706 & 213 & 5970 & $35(95 \% \mathrm{Cl} 31$ to 40$)$ & $36(95 \% \mathrm{Cl} 31$ to 41$)$ & $1.03(0.83$ to 1.23$)$ & 0.9 & $0.007(-0.10$ to 0.11$)$ \\
\hline Male & 101 & 2959 & 107 & 3145 & $34(95 \% \mathrm{Cl} 28$ to 41$)$ & $34(95 \% \mathrm{Cl} 28$ to 41$)$ & 0.99 (0.75 to 1.31$)$ & 1.0 & $-0.002(-0.15$ to 0.15$)$ \\
\hline Female & 100 & 2747 & 106 & 2825 & $36(95 \% \mathrm{Cl} 30$ to 44$)$ & $38(95 \% \mathrm{Cl} 31$ to 45$)$ & 1.03 (0.78 to 1.36$)$ & 0.8 & $0.01(-0.13$ to 0.17$)$ \\
\hline
\end{tabular}

VAS, vitamin A supplementation.

between the two groups (table 4). However, the proportion with severe retinol deficiency was significantly lower among the VAS group.

There were no differences in reported morbidities between the two arms of the study. The morbidity rates of diarrheal episodes, fever and rapid breathing and severe pneumonia were similar in both groups (table 5). Neonatal deaths (0-28 days) per protocol were comparable in both the placebo and intervention arms (48 vs $57, \mathrm{p}=0.59$ ). Similarly, no difference was documented in mortality at $0-6$ months (115 vs 128 , $\mathrm{p}=0.64)$. The intention to treat analysis also revealed similar results (table 6).

\section{DISCUSSION}

Our findings show that it was feasible for LHWs in Pakistan to deliver vitamin A supplements to newborn infants within 
72 hours of birth. Given the importance attached to postnatal visits in terms of impact on newborn survival, ${ }^{22}$ this is an important step in developing integrated packages for preventive care after birth. Thus the addition of neonatal vitamin A dosing to the repertoire of interventions that can be implemented in the immediate postnatal period and the first few days of life (eg, cord chlorhexidine application, ${ }^{19}$ breastfeeding promotion and oral polio, BCG and hepatitis B vaccines) is both feasible and potentially cost-effective. The LHWs and families did not report any significant adverse effects with the 50000 IU dose. Only one case was reported to have a bulging fontanel, which self-resolved within 72 hours, while another case of vomiting and suspected seizures was found to be well at examination and resolved within 24 hours. These data suggest that, overall, neonatal VAS is a safe intervention that can be administered by community health workers in community settings.

The key question is whether the intervention is effective with health and survival benefits. We did not find any impact on mortality at 6 months of age and the observed effects on morbidity were also marginal and non-significant. Several limitations must be recognised in our study. Our trial was designed to assess the feasibility and effectiveness in a large rural district but had a smaller sample size than other similar studies. ${ }^{7}$ We did not measure vitamin A status in mothers or newborns at baseline and hence it is difficult to ascertain the extent to which biochemical vitamin A deficiency was widespread in the target population. However, a recent national nutrition survey including these very districts has highlighted vitamin A deficiency on serum retinol estimation of $42.5 \%$ and $54 \%$ among women of reproductive age and children $<5$ years, respectively, from this district. $^{14}$

A similar burden has been documented in Africa with vitamin A deficiency as high as $43 \%$ with a higher prevalence in the rural population. Others have demonstrated somewhat lower levels. $^{2425}$

Our findings of a lack of significant benefit of neonatal VAS on survival at 6 months of age is at variance with other studies in south Asia. ${ }^{6-8}$ However, other studies in Africa have failed to show any benefits of neonatal VAS on survival. ${ }^{102326}$ Although some reviews have failed to show any mortality benefit of neonatal VAS, ${ }^{27}$ our previous assessment of the evidence suggested geographical variation in the response to neonatal VAS which could relate to prevalent maternal vitamin A or multiple micronutrient deficiencies. ${ }^{28}{ }^{29}$ Although some gender-related differences in outcomes and survival have been reported, ${ }^{30}$ we did not find any differences in outcomes among female infants. Previous studies of neonatal VAS have also reported mixed results on morbidity patterns. In Indonesia, neonatal VAS was associated with a reduced number of clinic visits. ${ }^{29} 31$ Our data on morbidity patterns also did not show any reduction in morbidity rates or hospitalisations with neonatal VAS.

Breast feeding provides protection against vitamin A deficiency even in populations where deficiency may be endemic. Our study population had almost universal breast feeding (98\%) in both the placebo and VAS arms. The lack of apparent benefit on mortality may also be because of protection from vitamin A deficiency conferred by exclusive breast feeding early in life. The blood samples at 6 months of age did show an impact on the proportion with severe vitamin A deficiency among the supplemented infants.

\section{CONCLUSION}

We conclude that the delivery and distribution of vitamin $\mathrm{A}$ is feasible through the public sector LHWs. However, recommendations with regard its inclusion in the repertoire of interventions must await further evidence of benefits and risks. Our study did not show any benefit on infant survival. Two of three large trials evaluating the impact of vitamin A on infant mortality have recently been published, demonstrating no benefits, ${ }^{10} 26$ although the study in India was associated with a $10 \%$ reduction in mortality at 6 months of age, ${ }^{8}$ once again lending support to the contention that the intervention may be relevant in populations with varying rates of maternal nutritional risks and vitamin A deficiency. Further recommendations on neonatal VAS must therefore await additional contextual analysis and targeting to populations at greatest risk, as well as comparison with alternative strategies. ${ }^{29} 32$

\section{Twitter Follow Kamran Sadiq at @sadiqkamran}

Acknowledgements We thank Lady Health Workers of the National Program for Family Planning and Primary Care for their exceptional support and all the staff of the study for their hard work. We would also like to thank Mr Asghar Ali Khan, Senior Manager Grants and Dr Farhana Shahid, Dr Sunil Hotwani, study supervisors, Mr Didar Alam, Coordinator, Research Labs at Aga Khan University for facilitation they provided for the study. We also acknowledge Professor Qamaruddin Nizami's contribution in the masking and randomisation process.

Contributors $Z A B$ conceived the study and as principal investigator was involved in all aspects of the study. SS was study coordinator and oversaw study implementation. SA and SS wrote the first draft and were responsible for subsequent and final versions of the manuscript. $Z A B$ reviewed and finalised the final version. $\mathrm{KS}, \mathrm{AH}$ and NA were involved in study design, analysis planning and interpretation of data. MH implemented the study at the field site. IA and ZB oversaw the data management, coordination and data cleaning. SC was involved in data analysis and interpretation of data. All authors reviewed and approved the final manuscript.

Funding This study was funded by PAIMAN (Pakistan Initiative for Mothers and Newborns)/John Snow Inc via a grant funded by USAID, Award Number: Sub-agreement \#36098-01 (USAID cooperative agreement

\#391-A-00-05-01037-00). The funding body provided clearance for the project design but, apart from field visits to review progress, did not influence the field trial or the data analysis procedures.

Competing interests None declared.

\section{Patient consent Obtained.}

Ethics approval This study was approved by the Ethical Review Committee of Aga Khan University, Karachi, Pakistan. All the respondents gave informed consent prior to completing the interviews.

Provenance and peer review Not commissioned; externally peer reviewed.

\section{REFERENCES}

1 Liu L, Oza S, Hogan D, et al. Global, regional, and national causes of child mortality in 2000-2013, with projections to inform post-2015 priorities: an updated systematic analysis. Lancet 2015;385:430-40.

2 Lawn JE, Blencowe H, Oza S, et al. Lancet Every Newborn Study Group. Every Newborn: progress, priorities, and potential beyond survival. Lancet 2014;384:189-205.

3 Bhutta ZA, Das JK, Bahl R, et al. Lancet Newborn Interventions Review Group; Lancet Every Newborn Study Group. Can available interventions end preventable deaths in mothers, newborn babies, and stillbirths, and at what cost? Lancet 2014;384:347-70.

4 Black RE, Victora CG, Walker SP, et al. Maternal and child undernutrition and overweight in low-income and middle-income countries. Lancet 2013;382:427-51.

5 Bhutta ZA, Das JK, Rizvi A, et al., Lancet Nutrition Interventions Review Group; Maternal and Child Nutrition Study Group. Evidence-based interventions for improvement of maternal and child nutrition: what can be done and at what cost? Lancet 2013;382:452-77.

6 Rahmathullah L, Tielsch JM, Thulasiraj RD, et al. Impact of supplementing newborn infants with vitamin $A$ on early infant mortality: community based randomised trial in southern India. BMJ 2003;327:254.

7 Klemm RD, Labrique AB, Christian P, et al. Newborn vitamin A supplementation reduced infant mortality in rural Bangladesh. Pediatrics 2008;122:e242-50.

8 Mazumder S, Taneja S, Bhatia K, et al. Neovita India Study Group. Efficacy of early neonatal supplementation with vitamin A to reduce mortality in infancy in Haryana, India (Neovita): a randomised, double-blind, placebo-controlled trial. Lancet 2015;385:1333-42.

9 Awasthi S, Peto R, Read S, et al. the DEVTA (Deworming and Enhanced Vitamin A) team. Vitamin A supplementation every 6 months with retinol in 1 million 
pre-school children in north India: DEVTA, a cluster-randomised trial. Lancet 2013;381:1469-77.

10 Edmond KM, Newton S, Shannon C, et al. Effect of early neonatal vitamin A supplementation on mortality during infancy in Ghana (Neovita): a randomised, double-blind, placebo-controlled trial. Lancet 2015;385:1315-23.

11 West KP Jr, Christian P, Labrique AB, et al. Effects of vitamin A or beta carotene supplementation on pregnancy-related mortality and infant mortality in rural Bangladesh: a cluster randomized trial. JAMA 2011;305:1986-95.

12 Benn CS, Fisker AB, Jørgensen MJ, et al. Conflicting evidence for neonatal vitamin A supplementation. Vaccine 2008;26:4111-12.

13 National Institute of Population Studies (NIPS) [Pakistan] and ICF International. Pakistan Demographic and Health Survey 2012-2013. Islamabad, Pakistan and Calverton, Maryland, USA: NIPS and ICF International, 2013. http://www.nips.org. pk/abstract_files/PDHS\%20Final\%20Report\%20as\%20of\%20Jan\%2022-2014.pdf

14 Hafeez A, Mohamud BK, Shiekh MR, et al, Pakistan National Nutrition Survey 2011: Nutrition Wing, Ministry of Health, Pakistan. Lady Health Workers programme in Pakistan: challenges, achievements and the way forward. J Pak Med Assoc 2011;61:210-15.

15 Bhutta ZA, Hafeez A, Rizvi A, et al. Reproductive, maternal, newborn, and child health in Pakistan: challenges and opportunities. Lancet 2013;381:2207-18.

16 Bhutta ZA, Soofi S, Cousens $S$, et al. Improvement of perinatal and newborn care in rural Pakistan through community-based strategies: a cluster-randomised effectiveness trial. Lancet 2011;377:403-12.

17 Turab A, Ariff S, Habib MA, et al. Improved accessibility of emergency obstetrics and newborn care (EmONC) services for maternal and newborn health: a community based project. BMC Pregnancy Childbirth 2013;13:136.

18 Soofi S, Cousens S, Imdad A, et al. Topical application of chlorhexidine to neonatal umbilical cords for prevention of omphalitis and neonatal mortality in a rural district of Pakistan: a community-based, cluster-randomised trial. Lancet 2012;379:1029-36.

19 National Institute of Population Studies (NIPS) [Pakistan], and Macro International Inc. Pakistan Demographic and Health Survey 2006-2007. Islamabad, Pakistan: National Institute of Population Studies and Macro International, 2008. http:// dhsprogram.com/pubs/pdf/FR200/FR200.pdf)
20 Hayes RJ, Moulton LH. Cluster randomised trials. London, UK: Chapman and Hall/ CRC Interdisciplinary Statistics, 2008.

21 Teglia CM, Gil García MD, Galera MM, et al. Enhanced high-performance liquid chromatography method for the determination of retinoic acid in plasma. Development, optimization and validation. J Chromatogr A 2014;1353:40-8.

22 Lassi ZS, Middleton PF, Crowther $C$, et al. Interventions to improve neonatal health and later survival: an overview of systematic reviews. EBioMedicine 2015;2:983-98.

23 Benn CS, Fisker AB, Napirna BM, et al. Vitamin A supplementation and BCG vaccination at birth in low birthweight neonates: two by two factorial randomised controlled trial. BMJ 2010;340:c1101.

24 Hotz C, Chileshe J, Siamusantu W, et al. Vitamin A intake and infection are associated with plasma retinol among preschool children in rural Zambia. Public Health Nutr 2012;15:1688-96.

25 Maziya-Dixon BB, Akineyele IO, Sanusi RA, et al. Vitamin A deficiency is prevalent in children less than 5 years of age in Nigeria. J Nutr 2006;136:2255-61.

26 Masanja H, Smith ER, Muhihi A, et al. Neovita Tanzania Study Group. Effect of neonatal vitamin A supplementation on mortality in infants in Tanzania (Neovita): a randomised, double-blind, placebo-controlled trial. Lancet 2015;385:1324-32.

27 Gogia S, Sachdev HS. Neonatal vitamin A supplementation for prevention of mortality and morbidity in infancy: systematic review of randomised controlled trials. BMJ 2009;338:b919.

28 Haider BA, Bhutta ZA. Neonatal vitamin A supplementation for the prevention of mortality and morbidity in term neonates in developing countries. Cochrane Database Syst Rev 2011;(10):CD006980.

29 Haider BA, Bhutta ZA. Neonatal vitamin A supplementation: time to move on. Lancet 2015;385:1268-71.

30 Benn CS, Aaby P, Arts RJ, et al. An enigma: why vitamin A supplementation does not always reduce mortality even though vitamin A deficiency is associated with increased mortality. Int J Epidemiol 2015;44:906-18.

31 Humphrey JH, Agoestina T, Wu L, et al. Impact of neonatal vitamin A supplementation on infant morbidity and mortality. J Pediatr 1996;128:489-96.

32 Basu S, Sengupta B, Roy Paladhi PK. Single megadose vitamin A supplementation of Indian mothers and morbidity in breastfed young infants. Postgrad Med J 2003;79:397-402. 


\section{ADC}

Evaluation of the uptake and impact of neonatal vitamin A supplementation delivered through the Lady Health Worker programme on neonatal and infant morbidity and mortality in rural Pakistan: an effectiveness trial

Sajid Soofi, Shabina Ariff, Kamran Sadiq, Atif Habib, Zaid Bhatti, Imran Ahmad, Masawar Hussain, Nabeela Ali, Simon Cousens and Zulfiqar A Bhutta

Arch Dis Child 2017 102: 216-223 originally published online June 28, 2016

doi: 10.1136/archdischild-2016-310542

Updated information and services can be found at:

http://adc.bmj.com/content/102/3/216

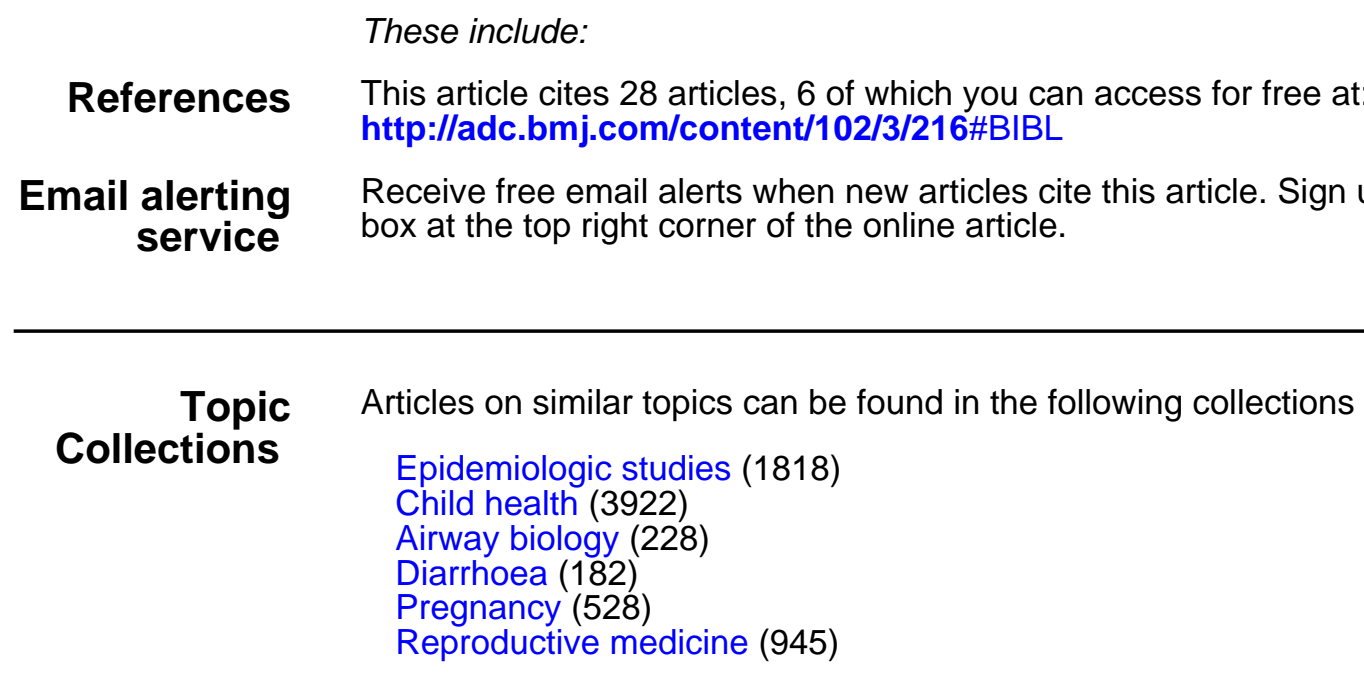

Notes

To request permissions go to:

http://group.bmj.com/group/rights-licensing/permissions

To order reprints go to:

http://journals.bmj.com/cgi/reprintform

To subscribe to BMJ go to:

http://group.bmj.com/subscribe/ 